\title{
Review Article \\ Core-Shell Structure in Doped Inorganic Nanoparticles: Approaches for Optimizing Luminescence Properties
}

\author{
Dini Xie, Hongshang Peng, Shihua Huang, and Fangtian You \\ Key Laboratory of Luminescence and Optical Information, Ministry of Education, Institute of Optoelectronic Technology, \\ Beijing Jiaotong University, Beijing 100044, China
}

Correspondence should be addressed to Hongshang Peng; hshpeng@bjtu.edu.cn

Received 10 May 2013; Revised 2 July 2013; Accepted 18 August 2013

Academic Editor: Pathik Kumbhakar

Copyright (C) 2013 Dini Xie et al. This is an open access article distributed under the Creative Commons Attribution License, which permits unrestricted use, distribution, and reproduction in any medium, provided the original work is properly cited.

Doped inorganic luminescent nanoparticles (NPs) have been widely used in both research and application fields due to their distinctive properties. However, there is an urgent demand to improve their luminescence efficiency, which is greatly reduced by surface effects. In this paper, we review recent advances in optimizing luminescence properties of doped NPs based on core-shell structure, which are basically classified into two categories: one is by use of surface coating with nonmetal materials to weaken the influence of surface effect and the other is with metal shell via metal enhanced luminescence. Different materials used to coat NPs are surveyed, and their advantages and disadvantages are both commented on. Moreover, problems in current core-shell structured luminescent NPs are pointed out and strategies furthering the optimization of luminescence properties are suggested.

\section{Introduction}

With the development of nanoscience and nanotechnology, more and more researches focus on core-shell nanostructures. A statistical data analysis is presented in Figure 1 to show an accelerated increase of published SCI papers on the theme of "core-shell nanoparticles." One motivation of using core-shell nanostructures is to achieve multiple functions. Usually, NPs have limited functions owing to the inherent property of constituted materials. Combining two or more kinds of materials into one particle, in the form of core-shell structure, is an effective way to address this issue. For instance, magnetic-luminescent bifunctional nanocomposites can be formed by coating magnetic NPs with a layer of luminescent material as a shell [1-7]. When magnetic NPs are surface modified by a layer of catalytic material, magnetic-catalytic core-shell NPs are obtained [8$16]$.

Another important motivation of utilizing core-shell nanostructure is to improve properties of NPs, such as luminescence efficiency. There are mainly two directions in enhancing luminescence properties of nanomaterial: inhibit the negative factors and promote the positive factors.

A great deal of studies including ours has demonstrated that luminescence efficiency and lifetime of materials will be greatly reduced compared with the bulk ones when their size is reduced to nanoscale [17-20]. This is usually ascribed to large surface area of nanomaterials, unsaturated bonds on the surface or high surface energy, which are prone to quench the luminescence of emission centers on or near the surface [21-24]. In view of this, surface coating in the form of a core-shell structure may efficiently eliminate these negative influences of surface effect on luminescence of doped NPs. On the other hand, radiative transition rate and excitation efficiency of luminescent species will be increased when the distance between luminescent species and noble metal is within a certain range $[25,26]$. Therefore, luminescent properties of doped NPs can be ameliorated via metal enhanced luminescence if a metal shell is coated around NPs.

This review mainly focuses on recent development of approaches for optimizing luminescence properties of inorganic doped NPs through core-shell structures. 


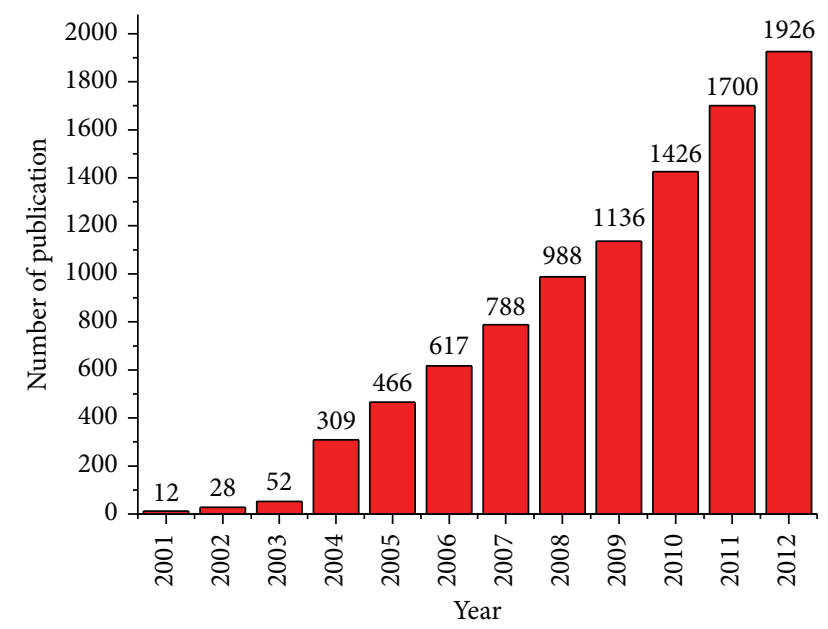

FIGURE 1: Publications per year for core-shell NPs during the period 2001 to 2012. The data was collected from Web of Science Database, using the keyword "core-shell nanoparticles" in the theme.

\section{Core-Shell Structure to Weaken Surface Effect}

For doped NPs, because of their limited sizes, sites occupied by doped ions can no more be considered as equivalent [27]. In NPs, therefore, inhomogeneous linewidth gets broader [28], originally degenerated energy levels may split [22], and selection rules may be loosened. Variations in the position of spectral lines and branching ratios can be observed with selective excitation [29]. Defects and disorders related to breakage of lattice periodicity on the large surface area of nanomaterials may introduce local electronic states into band gap, acting as traps for excitation. Besides, unsaturated bonds on surface render the particle surface very active, so that light ions and radicals may be adsorbed and attached onto the surface. Ions coupled with them would have high multiphonon relaxation rate and act also as traps. In many cases, surface provides an additional quench path for the luminescence of ion centers in NPs, resulting in fast decay and low quantum efficiency (QE) [30].

Wang et al. [31] presented direct evidence of surface quenching effect associated with size-dependent luminescence of upconversion (UC) NPs. The influence of surface quenching on decay curve and QE of ion centers in NPs was discussed by Huang and You [32], considering energy transfer between doped ions and surface quench centers. QE and decay curve under nonselective excitation were calculated numerically by integrating over the sample. Surface effect of nanophosphors was studied by time-resolved spectroscopy by Tian et al. [33], who suggested that surface quenching effects could be negligible when luminescence centers were more than $7 \mathrm{~nm}$ away from the surface.

For nondoped quantum dots (QDs), there are similar surface effects. Chou et al. [34] demonstrated that organic molecules on the surface of CdS QDs largely decreased photoluminescence (PL) quantum yield (QY) based on density function theory computation. They proposed that the interactions between capping molecules and CdS QDs might be attributed to functional groups and CdS clusters.

Core-shell structure is an effective way to weaken surface effect of NPs. According to the nature of adopted core material to that of shell material, core-shell nanostructures are approximately separated into "homogeneous" or "heterogeneous" in this review, corresponding to the same or different materials, respectively.

\subsection{Heterogeneous Core-Shell Nanostructures}

2.1.1. Silica Coating. For heterogeneous core-shell nanostructures, the shell can be classified into two categories: silica or nonsilica. Silica has the attributes of good biocompatibility, water solubility, and synthesis, hence, are widely used to coat NPs. Silica can withstand a high annealing temperature, which is helpful to enhance the crystalline of luminescent materials. Moreover, the thickness of silica shell can enlarge the distance between doped ions and surface quenching centers. Therefore, PL properties of doped NPs can be greatly enhanced through the decrease of nonradiative transition after silica coating.

Doped QDs were silica coated by microemulsion or precipitation method $[35,36]$. Compared to uncoated ZnS:Mn NPs, silica-coated ZnS:Mn NPs had improved PL intensity as well as good photostability. Rare-earth (RE) doped vanadate could be silica coated by Stöber method [37]. A remarkable luminescence enhancement up to 2.17 times was observed in colloidal $\mathrm{YVO}_{4}: \mathrm{Eu} @ \mathrm{SiO}_{2}$ nanocrystals (NCs), compared to that of bare $\mathrm{YVO}_{4}$ :Eu NCs. A significant improvement of luminescence intensity was also observed in $\mathrm{LaF}_{3}: \mathrm{Nd}^{3+} @ \mathrm{SiO}_{2}$ core-shell NPs [38]. The phenomenon was additionally ascribed to the change of environment of $\mathrm{LaF}_{3}: \mathrm{Nd}^{3+}$ core imposed by the silica shell.

A series of $\mathrm{Y}_{2} \mathrm{O}_{3}: \mathrm{Eu}^{3+} @ \mathrm{SiO}_{2}$ with different silica-coating thicknesses were synthesized by Liu et al. [39]. It was interesting to find that the silica shell not only changed the luminescence intensity of NPs but also led to the redistribution of ${ }^{5} \mathrm{D}_{0}-{ }^{7} \mathrm{~F}_{J}$ branch ratios under ${ }^{7} \mathrm{~F}_{J^{-}}{ }^{5} \mathrm{D}_{2}$ excitation. The increased intensity ratio of ${ }^{5} \mathrm{D}_{0}-{ }^{7} \mathrm{~F}_{2}$ to ${ }^{5} \mathrm{D}_{0}-{ }^{7} \mathrm{~F}_{J}(J \neq 2)$ was attributed to the thickening of silica shell, which decreased excitation power density and suppressed reabsorption. The variation of the effective refractive index of the core-shell composites led to the increase of lifetime with shell thickness, while the reduced reabsorption process decreased the lifetime. Therefore, an optimum lifetime appeared as a function of shell thickness.

RE-doped UC NPs is another type of important luminescent NPs largely due to their biological applications with nearinfrared (NIR) radiation [40]. The developed core-shell UC NPs are attractive due to their excellent photostability, highly efficient luminescence, and low toxicity with biocompatible shell material. UC luminescence intensity of silica-coated $\mathrm{NdF}_{3}$ was reported to about 1.6 times of bare $\mathrm{NdF}_{3} \mathrm{NPs}$ [41], and the effect of coating on the UC luminescence intensity in RE-doped $\mathrm{NaYF}_{4}$ UCNCs was strongly dependent on the volume ratio of the core and shell $[42,43]$. In another work, Lü et al. [44] presented that the UC luminescence intensity 


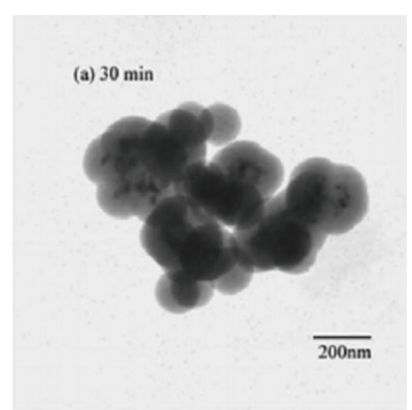

(a)

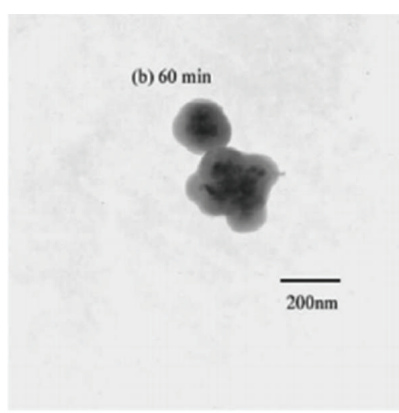

(b)

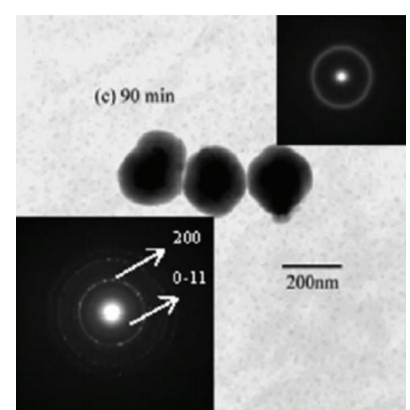

(c)

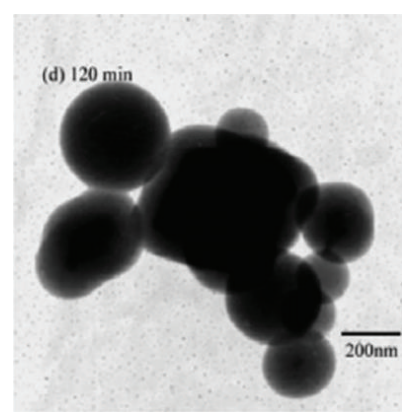

(d)

FIGURE 2: Transmission electron microscopy (TEM) photographs of silica-coated $\mathrm{Y}_{2} \mathrm{O}_{3}: \mathrm{Tm}^{3+}, \mathrm{Yb}^{3+} \mathrm{NPs}$ for the sintering time of 60 min and the coating time of $30 \mathrm{~min}$ (a), $60 \mathrm{~min}$ (b), $90 \mathrm{~min}$ (c), and $120 \mathrm{~min}$ (d), respectively. The upper inset (c) shows the electron diffraction (ED) pattern of noncrystalline silica shells and the lower inset is the corresponding ED pattern of crystalline $\mathrm{Y}_{2} \mathrm{O}_{3}: \mathrm{Tm}^{3+}, \mathrm{Yb}^{3+} \mathrm{core}^{[44]}$. Copyright 2008 American Institute of Physics.

of $\mathrm{Y}_{2} \mathrm{O}_{3}: \mathrm{Tm}^{3+}, \mathrm{Yb}^{3+}$ NPs was also enhanced with the coreshell structures. Comparing with the UC luminescence intensity of bare NPs, the UC luminescence intensities of silicacoated NPs with the sintering time of $60 \mathrm{~min}$ and the coating time of $30,60,90$, and 120 min were enhanced by $1.53,1.54$, 1.40 , and 1.16 times, respectively (Figure 2). According to the relative variable ratios of the UC luminescence intensities of silica-coated NPs, a competitive process between two mechanisms was proposed. One mechanism was the role conversion of RE ions on the surface of NPs from the dormant state to the activated state owing to complementary ligand fields from noncrystalline silica shells. The other mechanism was the absorption effects of the shells on incident pump light and the reabsorption effects on the UC luminescence. The role conversion of lanthanide ions was prevailing in thin shelled NPs, whereas the absorption and the reabsorption effects became predominant when a thicker silica shell is coated. Hence, an optimal thickness of silica shell was possible to achieve the maximum UC luminescence.

Although silica has been utilized to coat a variety of doped luminescent NPs, it has an inherent shortcoming: a large lattice mismatch commonly exists between amorphous silica shell and particle core. The consequent interface defects may give rise to additional luminescence quenching. Thus, a preferable core-shell structure to inhibit surface effects should be better lattice matched.

2.1.2. Nonsilica Coating. Zhu et al. [45] reported that $\mathrm{YVO}_{4}: \mathrm{Eu}^{3+} @ \mathrm{YBO}_{3}$ core-shell heteronanostructures exhibited much stronger PL than $\mathrm{YVO}_{4}: \mathrm{Eu}^{3+} \mathrm{NCs}$ under the same conditions. Shell ratio (SR) is the molar percentage of the shell material in the core-shell heteronanostructures, which is a critical factor in PL enhancement. The heteronanostructures exhibited the highest PL efficiency when $\mathrm{SR}=1 / 7$, whose PL intensity was $27 \%$ higher than that of the $\mathrm{YVO}_{4}$ : $\mathrm{Eu}^{3+}$ NCs. When SR $<1 / 7$, PL intensity increased with increasing SR. This was because the surface recombination, surface defects density and surface state density of $\mathrm{YVO}_{4}: \mathrm{Eu}^{3+} \mathrm{NCs}$ reduced with increasing the $\mathrm{YBO}_{3}$ coating. When SR $>1 / 7$, PL intensity decreased with increasing molar percentage of the nonluminescent shell material. Lin et al. [46-48] prepared $\mathrm{CeF}_{3}, \mathrm{CeF}_{3}: \mathrm{Tb}^{3+}$, and $\mathrm{CeF}_{3}: \mathrm{Tb}^{3+} @ \mathrm{LaF}_{3}$ core-shell NPs which show characteristic emission of $\mathrm{Ce}^{3+}(5 \mathrm{~d}-4 \mathrm{f})$ and $\mathrm{Tb}^{3+}(\mathrm{f}-$ f) respectively. When the $\mathrm{CeF}_{3}: \mathrm{Tb}^{3+} \mathrm{NPs}$ were coated with the $\mathrm{LaF}_{3}$ shells, the emission intensity was improved by $28 \%$ with respect to that of $\mathrm{CeF}_{3}: \mathrm{Tb}^{3+}$ core NPs. The energyloss processes on the surface luminescence centers could be significantly decreased by the $\mathrm{LaF}_{3}$ shell which provided a barrier for energy migration to the outer surface of the shell, and thus the luminescence intensity and lifetime of the core-shell NPs were greatly enhanced. Boyer et al. [49] synthesized $\mathrm{NaGdF}_{4}: \mathrm{Tb}^{3+}, \mathrm{Ce}^{3+} @ \mathrm{NaYF}_{4} \mathrm{NPs}$ that formed colloidal solutions in nonpolar organic solvents and showed green luminescence under ultraviolet (UV) excitation. Coreshell NPs demonstrated higher QY ( 30\%) under UV light and greater resistance to cerium oxidation when compared to the core-only NPs.

Kömpe et al. [50] obtained $\mathrm{CePO}_{4}: \mathrm{Tb} @ \mathrm{LaPO}_{4}$ core-shell NPs with a total QY of $80 \%$, which was quite close to the value of the bulk material. Further recommendations of enhancing QY of NPs included optimizing the thickness of the shell and employing metal salts of extremely high purity. Another work showed that the luminescence properties of $\mathrm{Ce}^{3+}$ and $\mathrm{Tb}^{3+}$ ions in doped $\mathrm{CePO}_{4}$ and $\mathrm{LaPO}_{4}$ core and core-shell NPs did not only differ with respect to their QYs [51]. The $\mathrm{Ce}^{3+}$ emission in core NPs was red-shifted compared to core-shell particles. Energy transfer from excited states in volume sites to surface sites was responsible for this observation.

A strong linear dependence of the $\mathrm{NaGdF}_{4}$ shell thickness on the optical response of the hexagonal $\mathrm{NaYF}_{4}: \mathrm{Yb}$,Er@ $\mathrm{NaGdF}_{4}$ core-shell UCNCs had been presented by Zhang et al. [52]. During growth of the $\mathrm{NaGdF}_{4}$ shells, surface defects of the NCs could be gradually passivated by the shell deposition process, which resulted in the obvious enhancement of the overall UC emission intensity and lifetime and more resistant to quenching by water molecules. Another work reported that $\mathrm{NaGdF}_{4}: \mathrm{Yb}$,Er@ $\mathrm{NaYF}_{4}$ core-shell NPs with narrow size distribution $(\sigma<10 \%)$ were prepared by one pot successive layer-by-layer (SLBL) strategy [53]. Shell thickness of 
the obtained NPs could be well controlled from 1 monolayer (ML) $(\sim 0.36 \mathrm{~nm})$ to more than $20 \mathrm{ML}(\sim 8 \mathrm{~nm})$ by simply tuning the amounts of shell precursors, which resulted in the significant improving on UC luminescence efficiency (up to $0.51 \pm 0.08 \%$ ) and stability (more resistant to quenching by water). It was important to note that nearly $30 \%$ luminescence was quenched by water even after over coated with a $16 \mathrm{ML}(\sim 5.5 \mathrm{~nm})$ shell. It was assumed that the high-energy stretching vibration of the water molecule could be regarded as a surface oscillator. The interaction between this oscillator and the luminescence center (lanthanide ions) might also be realized without contacting. It meant that the luminescence could be quenched by water with the noncontacting way, which was somewhat like the fluorescence resonance energy transfer (FRET). Chen et al. [54] reported novel $\alpha-\left(\mathrm{NaYbF}_{4}: 0.5 \% \mathrm{Tm}^{3+}\right) @ \mathrm{CaF}_{2}$ core-shell NPs with efficient $\mathrm{NIR}_{\text {in }}-\mathrm{NIR}_{\text {out }}$ UC PL and their applications for high-contrast in vitro and deep tissue bioimaging. An epitaxial $\mathrm{CaF}_{2}$ heteroshell increased the intensity of UC PL from $\alpha-\mathrm{NaYbF}_{4}: 0.5 \% \mathrm{Tm}^{3+} \mathrm{NPs} 35$ times. The QY of NIR UC $\mathrm{PL}$ in the $\alpha-\left(\mathrm{NaYbF}_{4}: 0.5 \% \mathrm{Tm}^{3+}\right) @ \mathrm{CaF}_{2}$ core-shell NPs was measured to be $0.60 \pm 0.1 \%$ under low-energy excitation of $0.3 \mathrm{~W} / \mathrm{cm}^{2}$.

Core-shell nanostructures with improved luminescence properties have been widely applied in various fields. For more examples and detailed informations on applications of different core-shell NPs, readers are referred to some other excellent reviews by Kalele et al. [55], Selvan et al. [56], Wang et al. [40], and so forth.

2.2. Homogeneous Core-Shell Nanostructures. Homogeneous core-shell nanostructures usually refer to doped core-shell nanostructures which adopt the same matrix material for the core and shell, containing dopant ions in the core, while the shell is pure matrix material or doped with other ions. The advantage of homogeneous core-shell nanostructure is the following. There is almost no problem of lattice mismatch between the core and shell, so that there will be fewer defects and quenching centers on the interfaces. In addition, since the shell and core have the same matrix, the shell is possible to transfer energy to the dopant ions in the vicinity of the surface of the core, and the overall absorption and emission intensity will be improved.

Quan et al. [57] observed a 30\% PL intensity enhancement in ZnS:Mn@ZnS core-shell NCs comparing with bare ZnS:Mn, which was ascribed to the elimination of the surface defects. Q. Xiao and C. Xiao [58] also reported a similar phenomenon and conclusion in ZnS:Mn@ZnS coreshell NPs. Cao et al. [59] demonstrated that $\mathrm{Mn}^{2+}$ emission at $580 \mathrm{~nm}$ in the ZnS:Mn@ZnS core-shell NPs was seven times stronger than that in the uncoated $\mathrm{ZnS}: \mathrm{Mn}$. Their experiment results indicated that both $\mathrm{ZnS}$ shell and UV light treatment (samples are exposed to the irradiation of a UV lamp $[60,61])$ could passivate nanoparticle surface, remove nonradiative relaxation paths, and thus enhance the overall luminescence quantum yield of uncoated $\mathrm{ZnS}: \mathrm{Mn}$. However, UV light treatment could only enhance the luminescence in the uncoated $\mathrm{ZnS}: \mathrm{Mn}$ NPs but led to no luminescence enhancement in the coated ones. Some calculations indicated that $\mathrm{Mn}^{2+}$ ions were not randomly distributed in the particle but preferred to occupy the sites close to the surface. This may be related to the "self-purification" process of nanomaterials [62], whereby $\mathrm{Mn}^{2+}$ has a tendency to be expelled to the nanoparticle surface [63]. Jiang et al. [64] studied the shell thickness dependence of luminescence intensity in core-shell ZnS:Mn@ZnS NPs. As the ZnS shell on the ZnS:Mn NPs thickened, an increase in the intensity of $\mathrm{Mn}^{2+}$ emission followed by a steady decline could be observed. The concentration of the luminescence center gradually decreased with shell thickening, which would consequently contribute a reducing effect to the emission intensity.

$\mathrm{Qu}$ et al. [65] synthesized $\mathrm{LaF}_{3}: \mathrm{Yb}^{3+}, \mathrm{Er}^{3+} @ \mathrm{LaF}_{3}$ which showed improvement in both the UC emission intensity and the lifetime. The enhancement could be attributed to the $\mathrm{LaF}_{3}$ shell which could eliminate the nonradiative centers on the surface of $\mathrm{LaF}_{3}: \mathrm{Yb}^{3+}, \mathrm{Er}^{3+} \mathrm{NCs}$. Qian et al. [66] increased the emission intensity of $\mathrm{NaYF}_{4}: \mathrm{Yb}, \mathrm{Er} @$ silica coreshell NPs by depositing an undoped $\mathrm{NaYF}_{4}$ shell on the $\mathrm{NaYF}_{4}: \mathrm{Yb}$,Er NPs before the silica coating (Figure 3). The total emission intensity of $\mathrm{NaYF}_{4}: \mathrm{Yb}, \mathrm{Er} @ \mathrm{NaYF}_{4} @$ silica coreshell NPs increased by 15 times compared to that without the intermediate $\mathrm{NaYF}_{4}$ shell. The critical shell thickness of $\mathrm{NaYF}_{4}$ was $\sim 3 \mathrm{~nm}$, beyond which no further emission intensity enhancement was observed.

Yi et al. [67] reported a significant UC luminescence enhancement after growing YOF shell on the surface of YOF:Yb,Er core. They observed that the YOF shell enhanced the red emission band at $\sim 669 \mathrm{~nm}$ but suppressed the green emission band at $\sim 540 \mathrm{~nm}$. The emission intensity at $\sim 669 \mathrm{~nm}$ was increased by $\sim 18.5$ times after coating. A steady increase in the red/green emissions $(R / G)$ ratio was observed during the growth of the NPs, which was due to host (matrix) effect of YOF.

In a sensitizer-activator UC system containing both sensitizer ions and activator ions [68], sensitizer ions could also be doped in the shell to make additional enhancement of UC luminescence. Vetrone et al. [69] demonstrated the synthesis of a novel $\mathrm{NaGdF}_{4}: \mathrm{Yb}, \mathrm{Er} @ \mathrm{NaGdF}_{4}: \mathrm{Yb}$ activecore@active-shell architecture with great enhancement of UC luminescence. Yang et al. [70] also reported the synthesis of $\mathrm{BaGdF}_{5}: \mathrm{Yb}, \mathrm{Er} @ \mathrm{BaGdF}_{5}: \mathrm{Yb}$ active-core@active-shell structured UCNCs with a controllable size from 3 to $10 \mathrm{~nm}$. It was found that after coating, the active shell with altered concentrations of $\mathrm{Yb}^{3+}$ ions in the shell, the luminescence intensity can be improved several hundred times. In contrast to the inert-shell-coated NPs, the main difference is that the active shell not only protects the luminescent ions from the nonradiative decay but also transfers absorbed radiation to the luminescent core.

Chen et al. [71] reported $\mathrm{NaGdF}_{4}: \mathrm{Nd@NaGdF}$ core-shell near-infrared downconversion NPs with an average size of $15 \mathrm{~nm}$ and exceptionally high PL QY. The fact that both the excitation and PL of these NCs were in the biological window of optical transparency, combined with their high $\mathrm{QE}$, spectral sharpness, and photostability, made them quite promising as optical biomaging probes. 


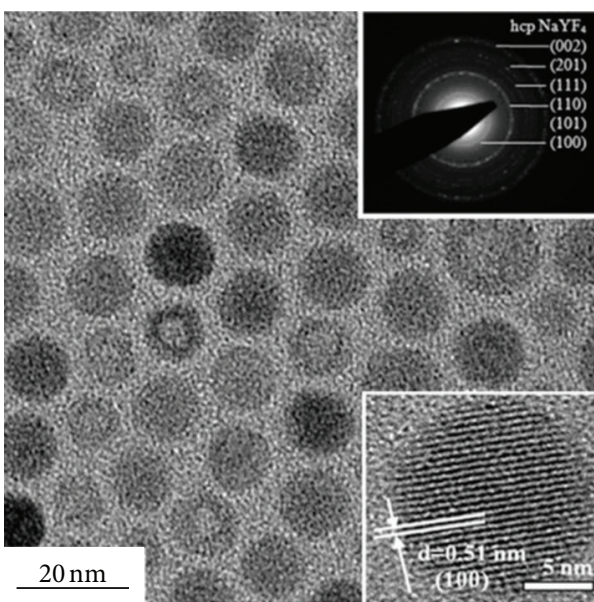

(a)

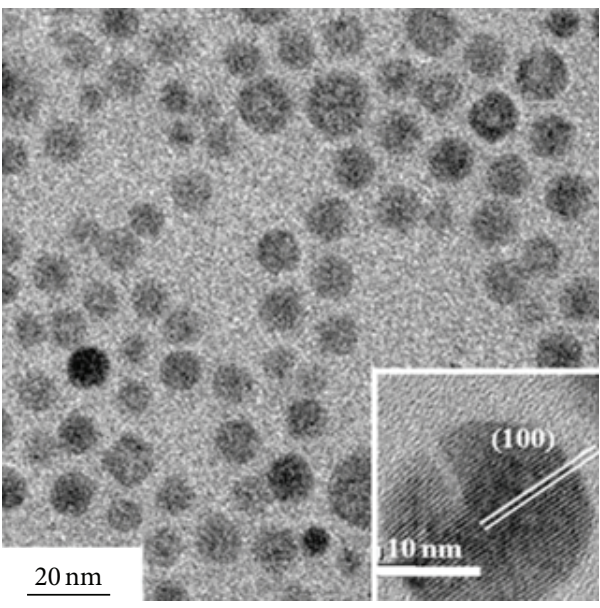

(c)

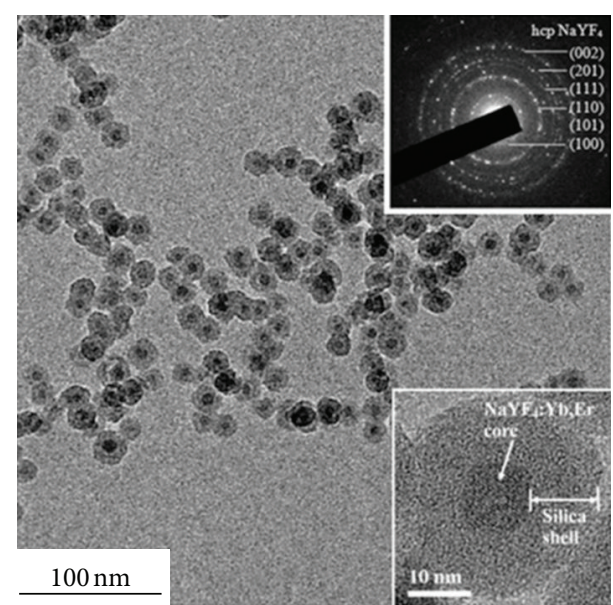

(b)

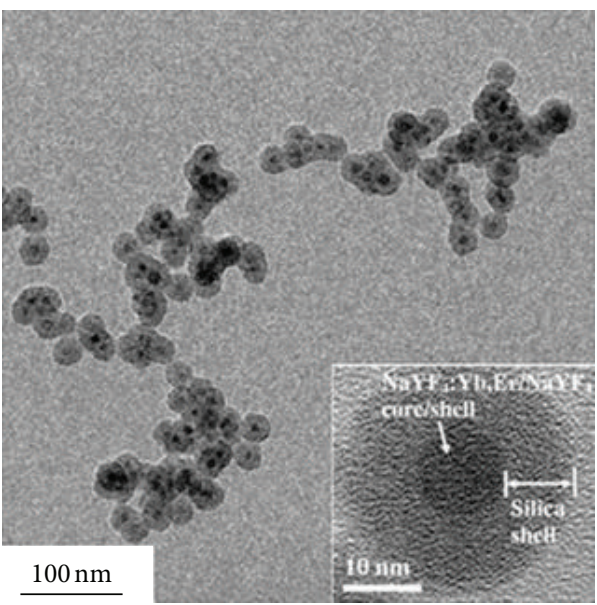

(d)

Figure 3: TEM images and HRTEM images (bottom inset) of (a) the $\mathrm{NaYF}_{4}: \mathrm{Yb}, \mathrm{Er} \mathrm{NPs}$, (b) the NaYF :Yb,Er@silica NPs, (c) the $\mathrm{NaYF}_{4}: \mathrm{Yb}, \mathrm{Er} @ \mathrm{NaYF}_{4} \mathrm{NPs}$, and (d) the $\mathrm{NaYF}_{4}: \mathrm{Yb}, \mathrm{Er} @ \mathrm{NaYF}_{4} @$ silica NPs. Diffraction patterns (top inset) of (a) the NaYF $\mathrm{Yb}_{4}: \mathrm{Yb} \mathrm{NPs}$ and (b) the $\mathrm{NaYF}_{4}: \mathrm{Yb}$,Er@silica NPs [66]. Copyright 2009 Materials Research Society.

2.3. The Possible Problem: Atom/Ion Diffusion in Core-Shell Nanostructures. As we see, most of the researches of coreshell nanomaterials concentrate on the method of preparing core-shell structures and the improved luminescence properties, but little attention has been devoted to the diffusion of doped ions in the core-shell nanomaterials. Ningthoujam et al. [72] presented the possibility of $\mathrm{Eu}^{3+}$ diffusion in $\mathrm{YVO}_{4}: \mathrm{Eu}^{3+} @ \mathrm{YVO}_{4}$ core-shell NPs. In this work, $\mathrm{YVO}_{4}: \mathrm{Eu}^{3+}$ $\mathrm{NPs}$ and $\mathrm{YVO}_{4}: \mathrm{Eu}^{3+} @ \mathrm{YVO}_{4}$ core-shell NPs were prepared and heat treated from 500 to $900^{\circ} \mathrm{C}$. Surface inhomogenities around $\mathrm{Eu}^{3+}$ present on the surface of the $\mathrm{YVO}_{4}: \mathrm{Eu}^{3+}$ core could be removed effectively by the undoped $\mathrm{YVO}_{4}$ shell and resulted in improved luminescence from coreshell NPs compared to the core NPs. Another reason of luminescence improvement could be that a small fraction of $\mathrm{Eu}^{3+}$ ions available on the surface of the core migrated into the $\mathrm{YVO}_{4}$ shell and led to the increase of $\mathrm{Eu}^{3+}-\mathrm{Eu}^{3+}$ distance and hence, reduced the extent of concentration quenching.
In view of this, the temperature of ions' diffusion and its influences on properties of core-shell nanomaterials should be investigated in order to achieve best luminescence properties. DiMaio et al. [73] studied the diffusion of $\mathrm{Eu}^{3+}$ ions in $\mathrm{LaF}_{3}: \mathrm{Eu}^{3+} @ \mathrm{LaF}_{3}$ core-shell NPs under $650^{\circ} \mathrm{C}$. At elevated temperatures, the diffusion of doped ions was significant enough to result in drastic color changes as emissions from higher-energy manifolds were no longer concentration quenched. In another work, Zheng et al. [74] observed $\mathrm{Mn}^{2+}$ diffusion in MnS@ZnS core-shell NCs annealed at relatively lower temperatures $\left(220-300^{\circ} \mathrm{C}\right)$. The diffusion of $\mathrm{Mn}^{2+}$ in MnS@ZnS NCs from the MnS core to the nanocrystal surface resulted in the PL surface quenching. Therefore, highly efficient luminescent NCs could be obtained by growing a thin $\mathrm{ZnS}$ shell on a small-sized $\mathrm{MnS}$ core at low temperature, annealing the resulting NCs for effectively diffusing $\mathrm{Mn}^{2+}$ into the $\mathrm{ZnS}$ shell at high temperature to form a $\mathrm{ZnS}: \mathrm{Mn}$ diffusion layer, and overcoating a thicker $\mathrm{ZnS}$ shell as a passivating layer. 
In a word, atom/ion diffusion should be concerned in the design and construction of core-shell nanostructures, especially when high temperature is required. If doped ions in particle core diffuse across shell to surface, then surface effect cannot be prevented any more and surface quenching of luminescence still remains.

\section{Core-Shell Structure to Achieve Metal Enhanced Luminescence}

The luminescence $\mathrm{QE}$ is given by $\mathrm{QE}=k_{r} /\left(k_{r}+k_{\mathrm{nr}}\right)$, where $k_{r}$ is the radiative transition rate, and $k_{\mathrm{nr}}$ is the nonradiative transition rate. As aforementioned, core-shell structure can weaken the surface effect and thus reduce nonradiative transition rate, and ultimately improve the effective QE. In addition, enhancement of QE can also be expected if the radiative transition rate is increased, based on the above $\mathrm{QE}$ equation.

In 1960s, Strickler and Berg [75] discovered that the vibration dipole radiative decay rate increased as the increase of the refractive index of medium, and Srickler-Berg equation was given to describe the relationship of the two parameters, which indicated that placing luminescent species near the metal surface could be an effective way of improving sensitivity of luminescence detection. In the later 1970s, Drexhage approved that luminescent species distribution close to the surface of a metal such as gold and silver of their luminescent emission intensity was greatly increased compared to the free state luminescent emission intensity [76, 77], and a theoretical explanation was given $[78,79]$. The laboratory led by Professor Lakowics of the University of Maryland studied this particular phenomenon of luminescence enhanced effect from both theoretical and experimental aspects and applied it in the field of biosensing and biomedical [80-84]. Metal enhanced luminescence (MEL) is a through-space effect. That is, there would be enhanced luminescence only if there is a certain distance between the luminescent species to the metal surface. The energy of luminescent species under the excited state will transfer to the matrix in the form of nonradiative transition when the distance is below $5 \mathrm{~nm}$. The extent of quenching effect is inversely proportional to the cube of the distance [85]. The radiative transition rate of the luminescent species will rise when the distance is $5-20 \mathrm{~nm}$ [25]. This will result in the enhancement of QY, which is more prominent in the low QY luminescent species. In this distance, the enhancement of surface local electromagnetic field activates molecules close to the metal surface and leads to promotion of excitation efficiency, which is also beneficial to enhancement of luminescence QY. Mechanisms of MEL were summarized by Geddes and Lakowicz [26].

The metal-fluorophore interactions result in an increase in the quantum yield (i.e., emission intensity) of the fluorophore and a decrease in the lifetime of fluorophores owing to two phenomena: an enhanced local electric field and an increase in the intrinsic system decay rate. The first factor provides stronger excitation rates but does not modify the fluorescence lifetime of the molecules. The second factor increases the net nanoparticle quantum yield. Excellent demonstrations of MEL was made by Aslan et al. [86-88], who reported that by growing a layer of silica shell with fluorophores embedded within it on the nanoparticle of $\mathrm{Ag}$, the emission intensity was about 20-fold larger than that of the nanobubbles without Ag core. Zeng et al. [89] also designed $\mathrm{Au} @ \mathrm{SiO}_{2}$ core-shell NPs to enhance the efficiency of FRET based on QDs and R-phycoerythrin (RPE) in solution. $\mathrm{Li}$ et al. [90] synthesized carbon dots adsorbed $\mathrm{Ag@SiO}$ core-shell NPs and obtained a more than four-fold increase of luminescence intensity of carbon dots.

As we mentioned before, there would be enhanced luminescence only if there is a certain distance between the luminescent species to the metal surface. Thus, the thickness of the spacer between the luminescent species and the metal is a critical parameter for the achievement of MEL. Zhang et al. [91] systematically increased the silica spacer thickness to optimize Ag@SiO $\mathrm{SY}_{2} \mathrm{O}_{3}$ : Er nanostructure UC materials, and the average PL intensity reached a maximum value of 4-fold larger than that of the pure $\mathrm{Y}_{2} \mathrm{O}_{3}$ :Er at an optimal silica spacer thickness of $30 \mathrm{~nm}$. Ge et al. [92] observed that with the increase of silica dielectric thickness, the green UC emission intensity of $\mathrm{Au} @ \mathrm{SiO}_{2} @ \mathrm{Y}_{2} \mathrm{O}_{3}: \mathrm{Yb}$,Er core-shell NPs increased and reached a maximum of 9.59-fold enhancement when silica thickness is $\sim 40 \mathrm{~nm}$ (Figure 4). Yuan et al. [93] synthesized $\mathrm{NaYF}_{4}: \mathrm{Yb}, \mathrm{Er} @ \mathrm{SiO}_{2}$ core-shell structures with Ag NPs of two different sizes (15 and $30 \mathrm{~nm}$ ) attaching to the surface of silica shell. Optimum UC luminescence enhancement was observed over a separation distance of $10 \mathrm{~nm}$, and the maximum enhancement factors of 14.4-fold and 10.8-fold were observed when 15 and $30 \mathrm{~nm} \mathrm{Ag} \mathrm{NPs}$ were respectively used. It was also noted that dependence of the luminescence intensity on the separation distance between the metal NPs and chromophores was stronger for $15 \mathrm{~nm}$ Ag NPs compared to $30 \mathrm{~nm}$. As the separation distance increased, both radiative decay and energy transfer processes would slow down, whereas the radiative decay rate changed less rapidly with the separation distance for larger metal NPs compared to smaller NPs.

Li et al. [94] reported that the UC emission intensity of $\mathrm{NaYF}_{4}: \mathrm{Yb}, \mathrm{Er}, \mathrm{Gd}$ nanorods increased when the nanorods were coupled with gold NPs, but the UC emission intensity suppressed when the nanorods were surrounded by continuous Au shells. Since there was no spacer between the luminescent material and metal, quenching mechanism might compete with the enhancement mechanism close to the surface of nanorods. In the case of an Au shell completely surrounding the UC nanorod, the Au was allocated so compact that additional quenching prevailed. Moreover, the condensed gold shell might block the emission transmittance from the UC nanorods.

\section{Core-Shell Structure to Further Optimize Luminescence Properties of Nanoparticles}

Weakening surface effect is to inhibit the negative factors in luminescence of NPs, while metal enhancement effect can 

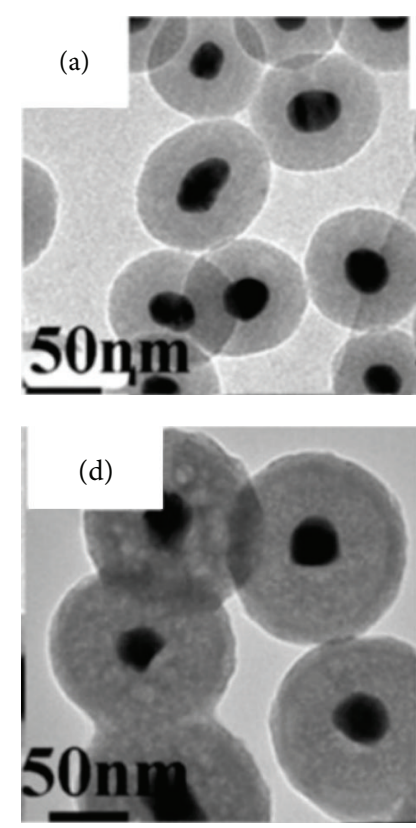
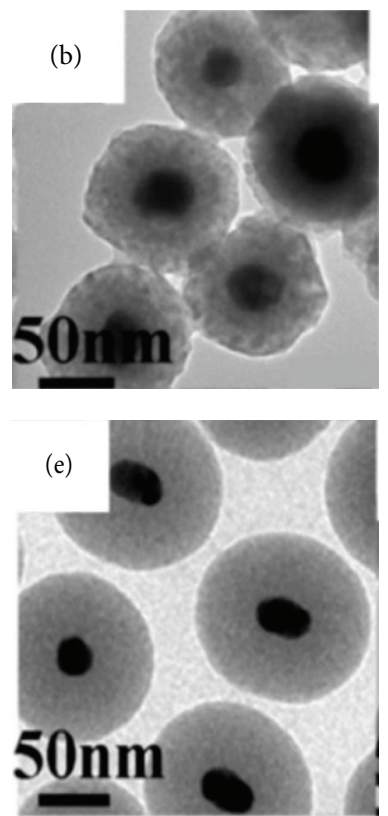
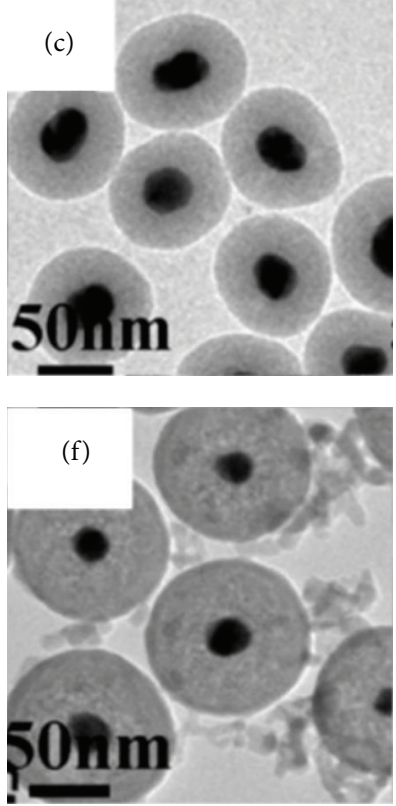
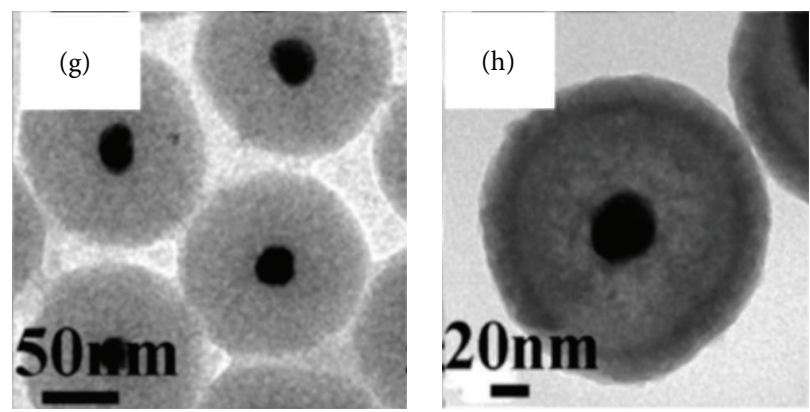

FIGURE 4: TEM images of (a) $\sim 30 \mathrm{~nm} \mathrm{Au} / \sim 25 \mathrm{~nm} \mathrm{SiO}_{2}$, (b) $\sim 30 \mathrm{~nm} \mathrm{Au} / \sim 25 \mathrm{~nm} \mathrm{SiO}{ }_{2} / \sim 12 \mathrm{~nm} \mathrm{Y}_{2} \mathrm{O}_{3}: \mathrm{Yb}^{3+}, \mathrm{Er}^{3+}$, (c) $\sim 30 \mathrm{~nm} \mathrm{Au} / \sim 30 \mathrm{~nm} \mathrm{SiO}{ }_{2}$, (d) $\sim 30 \mathrm{~nm} \mathrm{Au} / \sim 30 \mathrm{~nm} \mathrm{SiO}_{2} / \sim 12 \mathrm{~nm} \mathrm{Y}_{2} \mathrm{O}_{3}: \mathrm{Yb}^{3+}, \mathrm{Er}^{3+}$, (e) $\sim 30 \mathrm{~nm} \mathrm{Au} / 40 \mathrm{~nm} \mathrm{SiO}_{2}$, (f) $30 \mathrm{~nm} \mathrm{Au} / \sim 40 \mathrm{~nm} \mathrm{SiO}_{2} / \sim 12 \mathrm{~nm} \mathrm{Y}_{2} \mathrm{O}_{3}: \mathrm{Yb}^{3+}, \mathrm{Er}^{3+},(\mathrm{g})$ $\sim 30 \mathrm{~nm} \mathrm{Au} / \sim 45 \mathrm{~nm} \mathrm{SiO}_{2}$, and (h) $30 \mathrm{~nm} \mathrm{Au} / 45 \mathrm{~nm} \mathrm{SiO}_{2} / \sim 12 \mathrm{~nm} \mathrm{Y}_{2} \mathrm{O}_{3}: \mathrm{Yb}^{3+}, \mathrm{Er}^{3+}$ [92]. Copyright Ivyspring International Publisher.

promote the positive ones. It is possible to further optimize luminescence properties of core-shell NPs by combining the two paths together and the following points should be noted in design, and preparation of core-shell NPs.

(a) The noble metal is preferably located within the core. If the metal is located outside, its density should not be too high in order to avoid blocking of transmittance.

(b) The distance between metal and luminescent species should be controlled within a certain range.

(c) Lattice mismatch between core and shell should be minimized to prevent interface defects and luminescence quenching.

(d) Annealing is commonly needed to improve crystalline of NPs and to reduce defects.

(e) Thermal diffusion of atoms/ions in the shell of NPs should be concerned.

\section{Conclusions and Outlook}

This review seeks to summarize recent developments in optimizing luminescence properties of doped inorganic NPs with core-shell structures. Core-shell nanostructures can effectively prevent the influence of surface effect and reduce the nonradiative transition rate in NPs accordingly. On the other hand, MEL based core-shell structures can increase the radiative transition rate and excitation efficiency. Therefore, it is very promising to further optimize luminescence properties by combining the above two strategies into one core-shell nanostructure, despite the fact that the engineering and synthesis of such a complex nanostructure remain challenging. In addition, some other factors should be carefully considered when synthesizing doped core-shell NPs, such as nanoscale diffusion of atom/ion.

\section{Acknowledgments}

This work was financially supported by NSFC (Grants nos. 61078069 and 10979009), NCET (12-0771), and 
the Fundamental Research Funds for the Central Universities (2010JBZ006).

\section{References}

[1] H. Kim, M. Achermann, L. P. Balet, J. A. Hollingsworth, and V. I. Klimov, "Synthesis and characterization of Co/CdSe core/shell nanocomposites: bifunctional magnetic-optical nanocrystals," Journal of the American Chemical Society, vol.127, no. 2, pp. 544546, 2005.

[2] L. Zhang, B. Liu, and S. Dong, "Bifunctional nanostructure of magnetic core luminescent shell and its application as solidstate electrochemiluminescence sensor material," The Journal of Physical Chemistry B, vol. 111, no. 35, pp. 10448-10452, 2007.

[3] Y. Zhang, S. Pan, X. Teng, Y. Luo, and G. Li, "Bifunctional magnetic-luminescent nanocomposites: $\mathrm{Y}_{2} \mathrm{O}_{3} / \mathrm{Tb}$ nanorods on the surface of iron oxide/silica core-shell nanostructures," The Journal of Physical Chemistry C, vol. 112, no. 26, pp. 96239626, 2008.

[4] Y. Li, R. Yi, and X. Liu, "Synthesis and properties of Ni/ZnS magnetic luminescent bifunctional nanocomposites," Journal of Alloys and Compounds, vol. 486, no. 1-2, pp. L1-L4, 2009.

[5] J.-C. Zhou, L.-D. Sun, J. Shen, J.-Q. Gu, and C.-H. Yan, "Fluorescent-magnetic nanocrystals: synthesis and property of $\mathrm{YP}_{x} \mathrm{~V}_{1-x} \mathrm{O}_{4}: \mathrm{Eu} @ \mathrm{GdPO}_{4}$ core/shell structure," Nanoscale, vol. 3, no. 5, pp. 1977-1983, 2011.

[6] H. Peng, G. Liu, X. Dong, J. Wang, W. Yu, and J. Xu, "Magnetic, luminescent and core-shell structured $\mathrm{Fe}_{3} \mathrm{O}_{4} @ \mathrm{YF}_{3}: \mathrm{Ce}^{3+}, \mathrm{Tb}^{3+}$ bifunctional nanocomposites," Powder Technology, vol. 215, pp. 242-246, 2012.

[7] C. Zhong, P. Yang, X. Li et al., "Monodisperse bifunctional $\mathrm{Fe}_{3} \mathrm{O}_{4} @ \mathrm{NaGdF}_{4}: \mathrm{Yb} / \mathrm{Er} @ \mathrm{NaGdF}_{4}: \mathrm{Yb} / \mathrm{Er}$ core-shell nanoparticles," RSC Advances, vol. 2, no. 8, pp. 3194-3197, 2012.

[8] L. Wang, J. Luo, Q. Fan et al., "Monodispersed core-shell $\mathrm{Fe}_{3} \mathrm{O}_{4} @$ Au nanoparticles," The Journal of Physical Chemistry B, vol. 109, no. 46, pp. 21593-21601, 2005.

[9] C.-H. Jun, Y. J. Park, Y.-R. Yeon et al., "Demonstration of a magnetic and catalytic Co@Pt nanoparticle as a dual-function nanoplatform," Chemical Communications, no. 15, pp. 16191621, 2006.

[10] W. Chiu, P. Khiew, M. Cloke et al., "Heterogeneous seeded growth: synthesis and characterization of bifunctional $\mathrm{Fe}_{3} \mathrm{O}_{4} / \mathrm{ZnO}$ core/shell nanocrystals," The Journal of Physical Chemistry C, vol. 114, no. 18, pp. 8212-8218, 2010.

[11] G. Chen, S. Desinan, R. Nechache, R. Rosei, F. Rosei, and D. Ma, "Bifunctional catalytic/magnetic Ni@Ru core-shell nanoparticles," Chemical Communications, vol. 47, no. 22, pp. 6308-6310, 2011.

[12] A. J. Wang, Y. F. Li, Z. H. Li, J. J. Feng, Y. L. Sun, and J. R. Chen, "Amperometric glucose sensor based on enhanced catalytic reduction of oxygen using glucose oxidase adsorbed onto core-shell $\mathrm{Fe}_{3} \mathrm{O}_{4} @$ silica@Au magnetic nanoparticles," Materials Science and Engineering C, vol. 32, pp. 1640-1647, 2012.

[13] S. C. Pang, S. Y. Kho, and S. F. Chin, "Fabrication of magnetite/silica/titania core-shell nanoparticles," Journal of Nanomaterials, vol. 2012, Article ID 427310, 6 pages, 2012.

[14] Z. Wang, L. Shen, and S. Zhu, "Synthesis of core-shell synthesis of core-shell $\mathrm{Fe}_{3} \mathrm{O}_{4} @ \mathrm{SiO}_{2} @ \mathrm{TiO}_{2}$ microspheres and their application as recyclable photocatalysts," International Journal of Photoenergy, vol. 2012, Article ID 202519, 6 pages, 2012.
[15] M. Zhu, C. Wang, D. Meng, and G. Diao, "In situ synthesis of silver nanostructures on magnetic $\mathrm{Fe}_{3} \mathrm{O}_{4} @ \mathrm{C}$ core-shell nanocomposites and their application in catalytic reduction reactions," Journal of Materials Chemistry A, vol. 1, no. 6, pp. 2118-2125, 2013.

[16] G. Bai, L. Shi, Z. Zhao, Y. Wang, M. Qiu, and H. Dong, "Preparation of a novel $\mathrm{Fe}_{3} \mathrm{O}_{4} @ \mathrm{SiO}_{2} @ \mathrm{Ni}$-La-B magnetic coreshell nanocomposite for catalytic hydrogenation," Materials Letters, vol. 96, pp. 93-96, 2013.

[17] H. Peng, H. Song, B. Chen, S. Lu, and S. Huang, "Spectral difference between nanocrystalline and bulk $\mathrm{Y}_{2} \mathrm{O}_{3}: \mathrm{Eu}^{3+}$," Chemical Physics Letters, vol. 370, no. 3-4, pp. 485-489, 2003.

[18] H. Peng, H. Song, B. Chen et al., "Temperature dependence of luminescent spectra and dynamics in nanocrystalline $\mathrm{Y}_{2} \mathrm{O}_{3}: \mathrm{Eu}^{3+}$," Journal of Chemical Physics, vol. 118, no. 7, pp. 32773282, 2003.

[19] H. Peng, S. Huang, F. You, J. Chang, S. Lu, and L. Cao, "Preparation and surface effect analysis of trivalent europium-doped nanocrystalline $\mathrm{La}_{2} \mathrm{O}_{2} \mathrm{~S}$," The Journal of Physical Chemistry $B$, vol. 109, no. 12, pp. 5774-5778, 2005.

[20] H. Peng, S. Huang, L. Sun, and C. Yan, "Analysis of surface effect on luminescent properties of $\mathrm{Eu}^{3+}$ in $\mathrm{YVO}_{4}$ nanocrystals," Physics Letters A, vol. 367, no. 3, pp. 211-214, 2007.

[21] S. Berger, L. Schächter, and S. Tamir, "Photoluminescence as a surface-effect in nanostructures," Nanostructured Materials, vol. 8, no. 2, pp. 231-242, 1997.

[22] C.-H. Yan, L.-D. Sun, C.-S. Liao et al., " $\mathrm{Eu}^{3+}$ ion as fluorescent probe for detecting the surface effect in nanocrystals," Applied Physics Letters, vol. 82, no. 20, pp. 3511-3513, 2003.

[23] V. Sudarsan, F. C. J. M. van Veggel, R. A. Herring, and M. Raudsepp, "Surface $\mathrm{Eu}^{3+}$ ions are different than "bulk" $\mathrm{Eu}^{3+}$ ions in crystalline doped $\mathrm{LaF}_{3}$ nanoparticles," Journal of Materials Chemistry, vol. 15, no. 13, pp. 1332-1342, 2005.

[24] M. J. Milla, J. M. Ulloa, and A. Guzmn, "High optical sensitivity to ambient conditions of uncapped InGaAs surface quantum dots," Applied Physics Letters, vol. 100, no. 13, Article ID 131601, 2012.

[25] J. Kümmerlen, A. Leitner, H. Brunner, F. Aussenegg, and A. Wokaun, "Enhanced dye fluorescence over silver island films: analysis of the distance dependence," Molecular Physics, vol. 80, no. 5, pp. 1031-1046, 1993.

[26] C. D. Geddes and J. R. Lakowicz, "Metal-enhanced fluorescence," Journal of Fluorescence, vol. 12, no. 2, pp. 121-129, 2002.

[27] D. K. Williams, H. Yuan, and B. M. Tissue, "Size dependence of the luminescence spectra and dynamics of $\mathrm{Eu}^{3+}: \mathrm{Y}_{2} \mathrm{O}_{3}$ nanocrystals," Journal of Luminescence, vol. 83-84, pp. 297-300, 1999.

[28] B. Mercier, C. Dujardin, G. Ledoux, C. Louis, O. Tillement, and P. Perriat, "Confinement effects in sesquioxydes," Journal of Luminescence, vol. 119-120, pp. 224-227, 2006.

[29] J. C. Boyer, F. Vetrone, J. A. Capobianco, A. Speghini, and M. Bettinelli, "Variation of fluorescence lifetimes and judd-ofelt parameters between $\mathrm{Eu}^{3+}$ doped bulk and nanocrystalline cubic $\mathrm{Lu}_{2} \mathrm{O}_{3}$," The Journal of Physical Chemistry $B$, vol. 108, no. 52, pp. 20137-20143, 2004.

[30] J. A. Nelson, E. L. Brant, and M. J. Wagner, "Nanocrystalline $\mathrm{Y}_{2} \mathrm{O}_{3}$ :Eu phosphors prepared by alkalide reduction," Chemistry of Materials, vol. 15, no. 3, pp. 688-693, 2003.

[31] F. Wang, J. Wang, and X. Liu, "Direct evidence of a surface quenching effect on size-dependent luminescence of upconversion nanoparticles," Angewandte Chemie-International Edition, vol. 49, no. 41, pp. 7456-7460, 2010. 
[32] S. Huang and F. You, "Influence of surface quenching on luminescence dynamics of ion centers in nanocrystals," Journal of Luminescence, vol. 129, no. 12, pp. 1692-1694, 2009.

[33] L. J. Tian, Y. J. Sun, Y. Yu, X. G. Kong, and H. Zhang, "Surface effect of nano-phosphors studied by time-resolved spectroscopy of Ce $\mathrm{e}^{3+}$," Chemical Physics Letters, vol. 452, no. 1-3, pp. 188-192, 2008.

[34] H.-L. Chou, C.-H. Tseng, K. C. Pillai, B.-J. Hwang, and L.-Y. Chen, "Surface related emission in CdS quantum dots. DFT simulation studies," The Journal of Physical Chemistry C, vol. 115, no. 43, pp. 20856-20863, 2011.

[35] A. S. Ethiraj, N. Hebalkar, S. K. Kulkarni et al., "Enhancement of photoluminescence in manganese-doped $\mathrm{ZnS}$ nanoparticles due to a silica shell," Journal of Chemical Physics, vol. 118, no. 19, pp. 8945-8953, 2003.

[36] B. Dong, L. Cao, G. Su, W. Liu, H. Qu, and D. Jiang, "Synthesis and characterization of the water-soluble silica-coated $\mathrm{ZnS}: \mathrm{Mn}$ nanoparticles as fluorescent sensor for $\mathrm{Cu}^{2+}$ ions," Journal of Colloid and Interface Science, vol. 339, no. 1, pp. 78-82, 2009.

[37] Y. Wang, W. Qin, J. Zhang, C. Cao, S. Lü, and X. Ren, "Photoluminescence of colloidal $\mathrm{YVO}_{4}: \mathrm{Eu} / \mathrm{SiO}_{2}$ core/shell nanocrystals," Optics Communications, vol. 282, no. 6, pp. 1148-1153, 2009.

[38] P. Bo, C. Kai, G. Chao, and W. Wei, "The influence of $\mathrm{SiO}_{2}$ shell on fluorescent properties of $\mathrm{LaF}_{3}: \mathrm{Nd}^{3+} / \mathrm{SiO}_{2}$ core/shell nanoparticles," Journal of Nanomaterials, vol. 2010, Article ID 238792, 5 pages, 2010.

[39] T. Liu, W. Xu, X. Bai, and H. Song, "Tunable silica shell and its modification on photoluminescent properties of $\mathrm{Y}_{2} \mathrm{O}_{3}: \mathrm{Eu}_{3} @ \mathrm{SiO}_{2}$ nanocomposites," Journal of Applied Physics, vol. 111, no. 6, Article ID 064312, 2012.

[40] M. Wang, G. Abbineni, A. Clevenger, C. Mao, and S. Xu, "Upconversion nanoparticles: synthesis, surface modification and biological applications," Nanomedicine: Nanotechnology, Biology, and Medicine, vol. 7, no. 6, pp. 710-729, 2011.

[41] X.-F. Yu, L.-D. Chen, M. Li et al., "Highly efficient fluorescence of $\mathrm{NdF}_{3} / \mathrm{SiO}_{2}$ core/shell nanoparticles and the applications for in vivo NIR detection," Advanced Materials, vol. 20, no. 21, pp. 4118-4123, 2008.

[42] J. Shan and Y. Ju, "Controlled synthesis of lanthanide-doped $\mathrm{NaYF}_{4}$ upconversion nanocrystals via ligand induced crystal phase transition and silica coating," Applied Physics Letters, vol. 91, no. 12, Article ID 123103, 2007.

[43] R. Abdul Jalil and Y. Zhang, "Biocompatibility of silica coated $\mathrm{NaYF}_{4}$ upconversion fluorescent nanocrystals," Biomaterials, vol. 29, no. 30, pp. 4122-4128, 2008.

[44] Q. Lü, F. Guo, L. Sun, A. Li, and L. Zhao, "Silica-/titaniacoated $\mathrm{Y}_{2} \mathrm{O}_{3}: \mathrm{Tm}^{3+}, \mathrm{Yb}^{3+}$ nanoparticles with improvement in upconversion luminescence induced by different thickness shells," Journal of Applied Physics, vol. 103, no. 12, Article ID 123533, 2008.

[45] H. Zhu, H. Hu, Z. Wang, and D. Zuo, "Synthesis of $\mathrm{YVO}_{4}: \mathrm{Eu}^{3+} / \mathrm{YBO}_{3}$ heteronanostructures with enhanced photoluminescence properties," Nanoscale Research Letters, vol. 4, no. 9, pp. 1009-1014, 2009.

[46] Z. L. Wang, Z. W. Quan, P. Y. Jia et al., "A facile synthesis and photoluminescent properties of redispersible $\mathrm{CeF}_{3}, \mathrm{CeF}_{3}: \mathrm{Tb}^{3+}$, and $\mathrm{CeF}_{3}: \mathrm{Tb}^{3+} / \mathrm{LaF}_{3}$ (core/shell) nanoparticles," Chemistry of Materials, vol. 18, no. 8, pp. 2030-2037, 2006.

[47] C. Li, X. Liu, P. Yang, C. Zhang, H. Lian, and J. Lin, " $\mathrm{LaF}_{3}$, $\mathrm{CeF}_{3}, \mathrm{CeF}_{3}: \mathrm{Tb}^{3+}$, and $\mathrm{CeF}_{3}: \mathrm{Tb}^{3+} @ \mathrm{LaF}_{3}$ (core-shell) nanoplates: hydrothermal synthesis and luminescence properties," The Journal of Physical Chemistry C, vol. 112, no. 8, pp. 2904-2910, 2008.
[48] S. Gai, P. Yang, X. Li et al., "Monodisperse $\mathrm{CeF}_{3}, \mathrm{CeF}_{3}: \mathrm{Tb}^{3+}$, and $\mathrm{CeF}_{3}: \mathrm{Tb}^{3+} @ \mathrm{LaF}_{3}$ core/shell nanocrystals: synthesis and luminescent properties," Journal of Materials Chemistry, vol. 21, no. 38, pp. 14610-14615, 2011.

[49] J.-C. Boyer, J. Gagnon, L. A. Cuccia, and J. A. Capobianco, "Synthesis, characterization, and spectroscopy of $\mathrm{NaGdF}_{4}: \mathrm{Ce}^{3+}$, $\mathrm{Tb}^{3+} / \mathrm{NaYF}_{4}$ core/shell nanoparticles," Chemistry of Materials, vol. 19, no. 14, pp. 3358-3360, 2007.

[50] K. Kömpe, H. Borchert, J. Storz et al., "Green-emitting $\mathrm{CePO}_{4}$ : $\mathrm{Tb} / \mathrm{LaPO}_{4}$ core-shell nanoparticles with $70 \%$ photoluminescence quantum yield," Angewandte Chemie-International Edition, vol. 42, no. 44, pp. 5513-5516, 2003.

[51] K. Kömpe, O. Lehmann, and M. Haase, "Spectroscopic distinction of surface and volume ions in cerium(III)- and terbium(III)-containing core and core/shell nanoparticles," Chemistry of Materials, vol. 18, no. 18, pp. 4442-4446, 2006.

[52] F. Zhang, R. Che, X. Li et al., "Direct imaging the upconversion nanocrystal core/shell structure at the subnanometer level: shell thickness dependence in upconverting optical properties," Nano Letters, vol. 12, no. 6, pp. 2852-2858, 2012.

[53] X. Li, D. Shen, J. Yang et al., "Successive layer-by-layer strategy for multi-shell epitaxial growth: shell thickness and doping position dependence in upconverting optical properties," Chemistry of Materials, vol. 25, no. 1, pp. 106-112, 2012.

[54] G. Chen, J. Shen, T. Y. Ohulchanskyy et al., “ $\left(\alpha-\mathrm{NaYbF}_{4}\right.$ : $\left.\mathrm{Tm}^{3+}\right) / \mathrm{CaF}_{2}$ core/shell nanoparticles with efficient nearinfrared to near-infrared upconversion for high-contrast deep tissue bioimaging," ACS Nano, vol. 6, no. 9, pp. 8280-8287, 2012.

[55] S. Kalele, S. W. Gosavi, J. Urban, and S. K. Kulkarni, "Nanoshell particles: synthesis, properties and applications," Current Science, vol. 91, no. 8, pp. 1038-1052, 2006.

[56] S. T. Selvan, T. T. Y. Tan, D. K. Yi, and N. R. Jana, "Functional and multifunctional nanoparticles for bioimaging and biosensing," Langmuir, vol. 26, no. 14, pp. 11631-11641, 2010.

[57] Z. Quan, Z. Wang, P. Yang, J. Lin, and J. Fang, "Synthesis and characterization of high-quality $\mathrm{ZnS}, \mathrm{ZnS}: \mathrm{Mn}^{2+}$, and $\mathrm{ZnS}: \mathrm{Mn}^{2+} / \mathrm{ZnS}$ (Core/Shell) luminescent nanocrystals," Inorganic Chemistry, vol. 46, no. 4, pp. 1354-1360, 2007.

[58] Q. Xiao and C. Xiao, "Synthesis and photoluminescence of water-soluble $\mathrm{Mn}: \mathrm{ZnS} / \mathrm{ZnS}$ core/shell quantum dots using nucleation-doping strategy," Optical Materials, vol. 31, no. 2, pp. 455-460, 2008.

[59] L. Cao, J. Zhang, S. Ren, and S. Huang, "Luminescence enhancement of core-shell ZnS:Mn/ZnS nanoparticles," Applied Physics Letters, vol. 80, no. 23, pp. 4300-4302, 2002.

[60] C. Jin, J. Yu, L. Sun et al., "Luminescence of $\mathrm{Mn}^{2+}$ doped $\mathrm{ZnS}$ nanocrystallites," Journal of Luminescence, vol. 66-67, no. 1-6, pp. 315-318, 1995.

[61] J. Yu, H. Liu, Y. Wang et al., "Irradiation-induced luminescence enhancement effect of $\mathrm{ZnS}: \mathrm{Mn}^{2+}$ nanoparticles in polymer films," Optics Letters, vol. 22, no. 12, pp. 913-915, 1997.

[62] G. M. Dalpian and J. R. Chelikowsky, "Self-purification in semiconductor nanocrystals," Physical Review Letters, vol. 96, no. 22, Article ID 226802, 2006.

[63] P. H. Borse, D. Srinivas, R. F. Shinde, S. K. Date, W. Vogel, and S. K. Kulkarni, "Effect of $\mathrm{Mn}^{2+}$ concentration in $\mathrm{ZnS}$ nanoparticles on photoluminescence and electron-spin-resonance spectra," Physical Review B, vol. 60, no. 12, pp. 8659-8664, 1999. 
[64] D. Jiang, L. Cao, G. Su et al., "Shell thickness dependence of luminescence intensity in core/shell $\mathrm{ZnS}: \mathrm{Mn} / \mathrm{ZnS}$ nanoparticles," Materials Chemistry and Physics, vol. 115, no. 2-3, pp. 795798, 2009.

[65] Y. Qu, M. Li, L. Zhang, and L. Zhao, "Preparation and characterization of upconversion luminescent $\mathrm{LaF}_{3}: \mathrm{Yb}^{3+}, \mathrm{Er}^{3+} / \mathrm{LaF}_{3}$ core/shell nanocrystals," Applied Surface Science, vol. 258, no. 1, pp. 34-37, 2011.

[66] L. P. Qian, D. Yuan, G. S. Yi, and G. M. Chow, "Critical shell thickness and emission enhancement of $\mathrm{NaYF}_{4}$ : $\mathrm{Yb}, \mathrm{Er} / \mathrm{NaYF}_{4} /$ silica core/shell/shell nanoparticles," Journal of Materials Research, vol. 24, no. 12, pp. 3559-3568, 2009.

[67] G. Yi, Y. Peng, and Z. Gao, "Strong red-emitting near-infraredto-visible upconversion fluorescent nanoparticles," Chemistry of Materials, vol. 23, no. 11, pp. 2729-2734, 2011.

[68] C. Liu, L. Zhang, Q. Zheng, F. Luo, Y. Xu, and U. Weng, "Advances in the surface engineering of upconversion nanocrystals," Science of Advanced Materials, vol. 4, no. 1, pp. 1-22, 2012.

[69] F. Vetrone, R. Naccache, V. Mahalingam, C. G. Morgan, and J. A. Capobianco, "The active-core/active-shell approach: a strategy to enhance the upconversion luminescence in lanthanidedoped nanoparticles," Advanced Functional Materials, vol. 19, no. 18, pp. 2924-2929, 2009.

[70] D. Yang, C. Li, G. Li, M. Shang, X. Kang, and J. Lin, "Colloidal synthesis and remarkable enhancement of the upconversion luminescence of $\mathrm{BaGdF}_{5}: \mathrm{Yb}^{3+} / \mathrm{Er}^{3+}$ nanoparticles by activeshell modification," Journal of Materials Chemistry, vol. 21, no. 16, pp. 5923-5927, 2011.

[71] G. Chen, T. Y. Ohulchanskyy, S. Liu et al., "Core/shell $\mathrm{NaGdF}_{4}: \mathrm{Nd}^{3+} / \mathrm{NaGdF}_{4}$ nanocrystals with efficient nearinfrared to near-infrared downconversion photoluminescence for bioimaging applications," ACS Nano, vol. 6, no. 4, pp. 2969-2977, 2012.

[72] R. S. Ningthoujam, L. R. Singh, V. Sudarsan, and S. Dorendrajit Singh, "Energy transfer process and optimum emission studies in luminescence of core-shell nanoparticles: $\mathrm{YVO}_{4}: \mathrm{Eu}-\mathrm{YVO}_{4}$ and surface state analysis," Journal of Alloys and Compounds, vol. 484, no. 1-2, pp. 782-789, 2009.

[73] J. DiMaio, B. Kokuoz, T. L. James, T. Harkey, D. Monofsky, and J. Ballato, "Photoluminescent characterization of atomic diffusion in core-shell nanoparticles," Optics Express, vol. 16, no. 16, pp. 11769-11775, 2008.

[74] J. Zheng, W. Ji, X. Wang et al., "Improved photoluminescence of MnS/ZnS core/shell nanocrystals by controlling diffusion of $\mathrm{Mn}$ ions into the ZnS shell," The Journal of Physical Chemistry C, vol. 114, no. 36, pp. 15331-15336, 2010.

[75] S. J. Strickler and R. A. Berg, "Relationship between absorption intensity and fluorescence lifetime of molecules," The Journal of Chemical Physics, vol. 37, no. 4, pp. 814-822, 1962.

[76] K. H. Drexhage, "Influence of a dielectric interface on fluorescence decay time," Journal of Luminescence, vol. 1-2, pp. 693-701, 1970.

[77] K. H. Drexhage, "Interaction of light with monomolecular dye layers," in Progress in Optics, E. Wolf, Ed., North-Holland, Amsterdam, The Netherlands, 1974.

[78] J. Gersten and A. Nitzan, "Spectroscopic properties of molecules interacting with small dielectric particles," The Journal of Chemical Physics, vol. 75, no. 3, pp. 1139-1152, 1981.

[79] D. A. Weitz, S. Garoff, J. I. Gersten, and A. Nitzan, "The enhancement of Raman scattering, resonance Raman scattering, and fluorescence from molecules adsorbed on a rough silver surface," The Journal of Chemical Physics, vol. 78, no. 9, pp. 5324-5338, 1983.

[80] J. R. Lakowicz, "Radiative decay engineering: biophysical and biomedical applications," Analytical Biochemistry, vol. 298, no. 1, pp. 1-24, 2001.

[81] J. R. Lakowicz, Y. Shen, S. D’Auria et al., "Radiative decay engineering: 2. Effects of silver island films on fluorescence intensity, lifetimes, and resonance energy transfer," Analytical Biochemistry, vol. 301, no. 2, pp. 261-277, 2002.

[82] J. R. Lakowicz, "Radiative decay engineering 3. Surface plasmon-coupled directional emission," Analytical Biochemistry, vol. 324, no. 2, pp. 153-169, 2004.

[83] I. Gryczynski, J. Malicka, Z. Gryczynski, and J. R. Lakowicz, "Radiative decay engineering 4. Experimental studies of surface plasmon-coupled directional emission," Analytical Biochemistry, vol. 324, no. 2, pp. 170-182, 2004.

[84] J. R. Lakowicz, "Radiative decay engineering 5: metal-enhanced fluorescence and plasmon emission," Analytical Biochemistry, vol. 337, no. 2, pp. 171-194, 2005.

[85] A. Campion, A. Gallo, C. Harris, H. Robota, and P. Whitmore, "Electronic energy transfer to metal surfaces: a test of classical image dipole theory at short distances," Chemical Physics Letters, vol. 73, no. 3, pp. 447-450, 1980.

[86] K. Asian, J. R. Lakowicz, H. Szmacinski, and C. D. Geddes, "Metal-enhanced fluorescence solution-based sensing platform," Journal of Fluorescence, vol. 14, no. 6, pp. 677-679, 2004.

[87] K. Aslan, M. Wu, J. R. Lakowicz, and C. D. Geddes, "Fluorescent core-shell Ag@SiO 2 nanocomposites for metal-enhanced fluorescence and single nanoparticle sensing platforms," Journal of the American Chemical Society, vol. 129, no. 6, pp. 1524-1525, 2007.

[88] K. Aslan, M. Wu, J. R. Lakowicz, and C. D. Geddes, "Metal enhanced fluorescence solution-based sensing platform 2: fluorescent core-shell Ag@SiO ${ }_{2}$ nanoballs," Journal of Fluorescence, vol. 17, no. 2, pp. 127-131, 2007.

[89] Q. Zeng, Y. Zhang, X. Liu et al., "Au/ $/ \mathrm{SiO}_{2}$ core/shell nanoparticles enhancing fluorescence resonance energy transfer efficiency in solution," Chemical Communications, vol. 46, no. 35, pp. 6479-6481, 2010.

[90] C. Li, Y. Zhu, X. Zhang, X. Yang, and C. Li, "Metal-enhanced fluorescence of carbon dots adsorbed $\mathrm{Ag@SiO} 2$ core-shell nanoparticles," RSC Advances, vol. 2, no. 5, pp. 1765-1768, 2012.

[91] F. Zhang, G. B. Braun, Y. Shi et al., "Fabrication of $\mathrm{Ag} @ \mathrm{SiO}_{2} @ \mathrm{Y}_{2} \mathrm{O}_{3}$ : Er nanostructures for bioimaging: tuning of the upconversion fluorescence with silver nanoparticles," Journal of the American Chemical Society, vol. 132, no. 9, pp. 2850-2851, 2010

[92] W. Ge, X. Zhang, M. Liu, Z. Lei, R. Knize, and Y. Lu, "Distance dependence of gold-enhanced upconversion luminescence in $\mathrm{Au} / \mathrm{SiO}_{2} / \mathrm{Y}_{2} \mathrm{O}_{3}: \mathrm{Yb}^{3+}, \mathrm{Er}^{3+}$ nanoparticles," Theranostics, vol. 3, pp. 282-288, 2013.

[93] P. Yuan, Y. H. Lee, M. K. Gnanasammandham, Z. P. Guan, Y. Zhang, and Q. H. Xu, "Plasmon enhanced upconversion luminescence of $\mathrm{NaYF}_{4}: \mathrm{Yb}, \mathrm{Er} @ \mathrm{SiO}_{2} @ \mathrm{Ag}$ core-shell nanocomposites for cell imaging," Nanoscale, vol. 4, pp. 5132-5137, 2012.

[94] Z. Q. Li, S. Chen, J. J. Li et al., "Plasmon-enhanced upconversion fluorescence in $\mathrm{NaYF}_{4}: \mathrm{Yb} / \mathrm{Er} / \mathrm{Gd}$ nanorods coated with $\mathrm{Au}$ nanoparticles or nanoshells," Journal of Applied Physics, vol. 111, no. 1, Article ID 014310, 7 pages, 2012. 

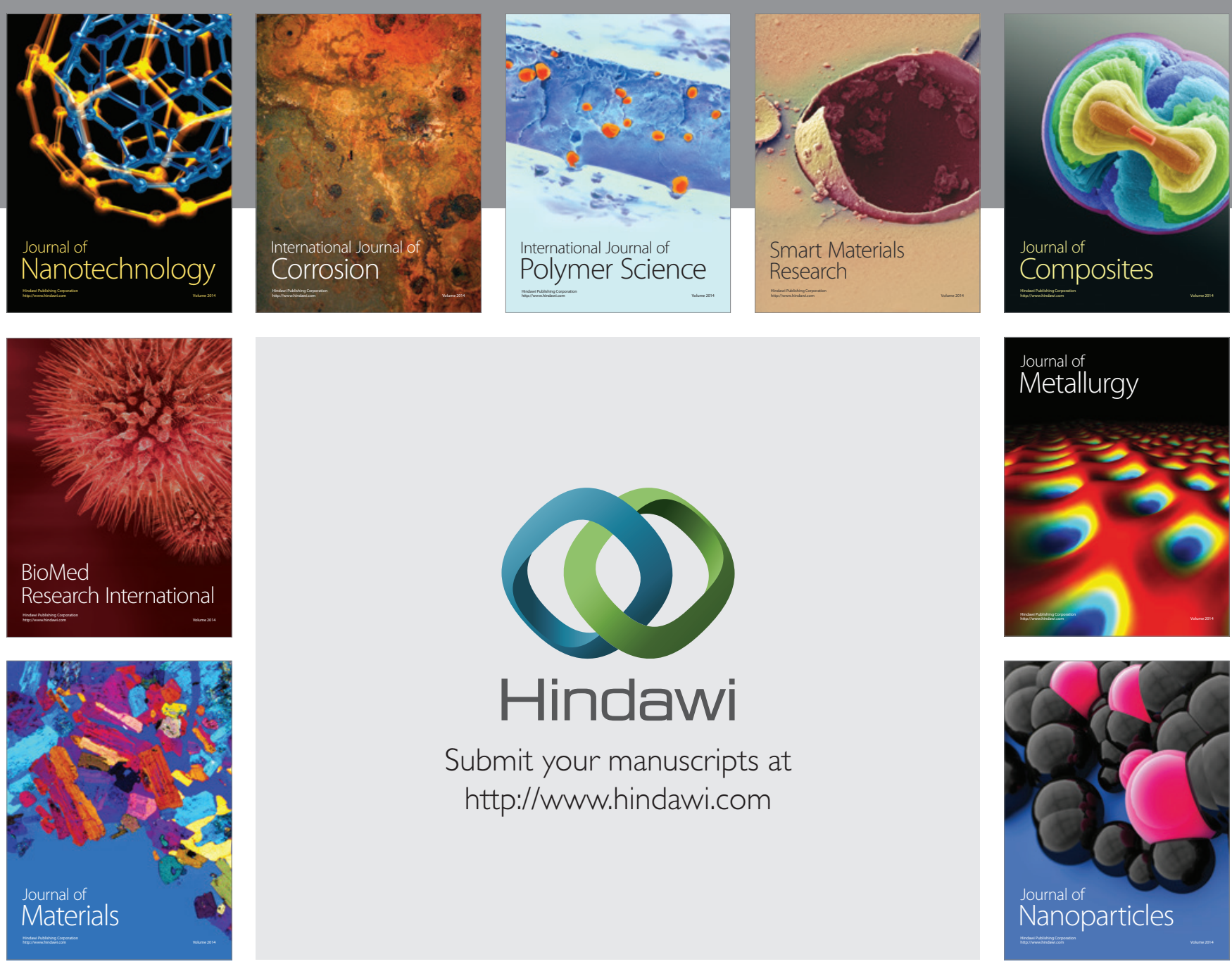

Submit your manuscripts at http://www.hindawi.com
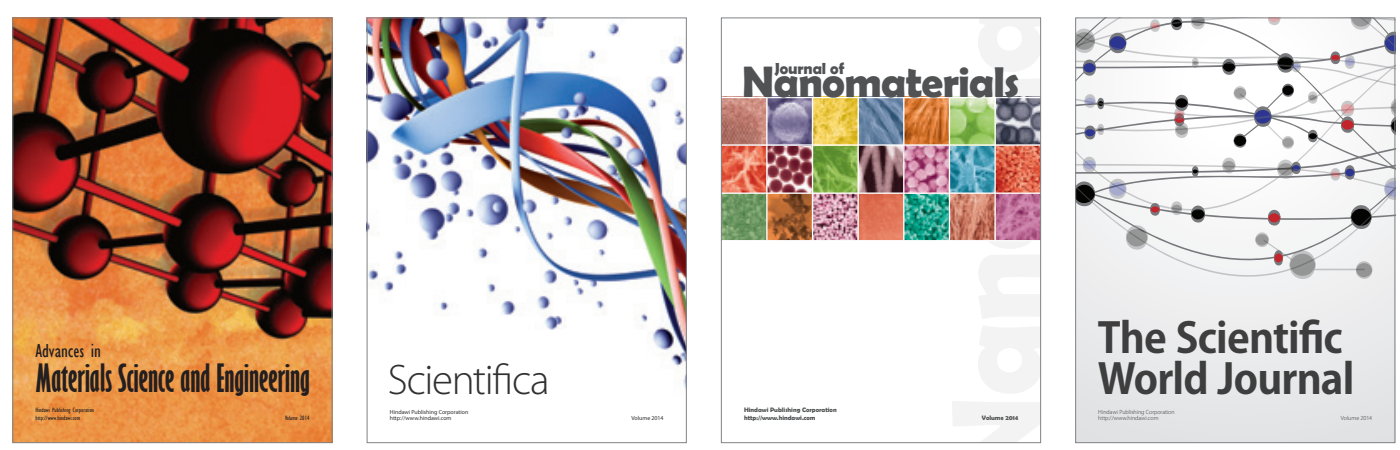

\section{The Scientific World Journal}
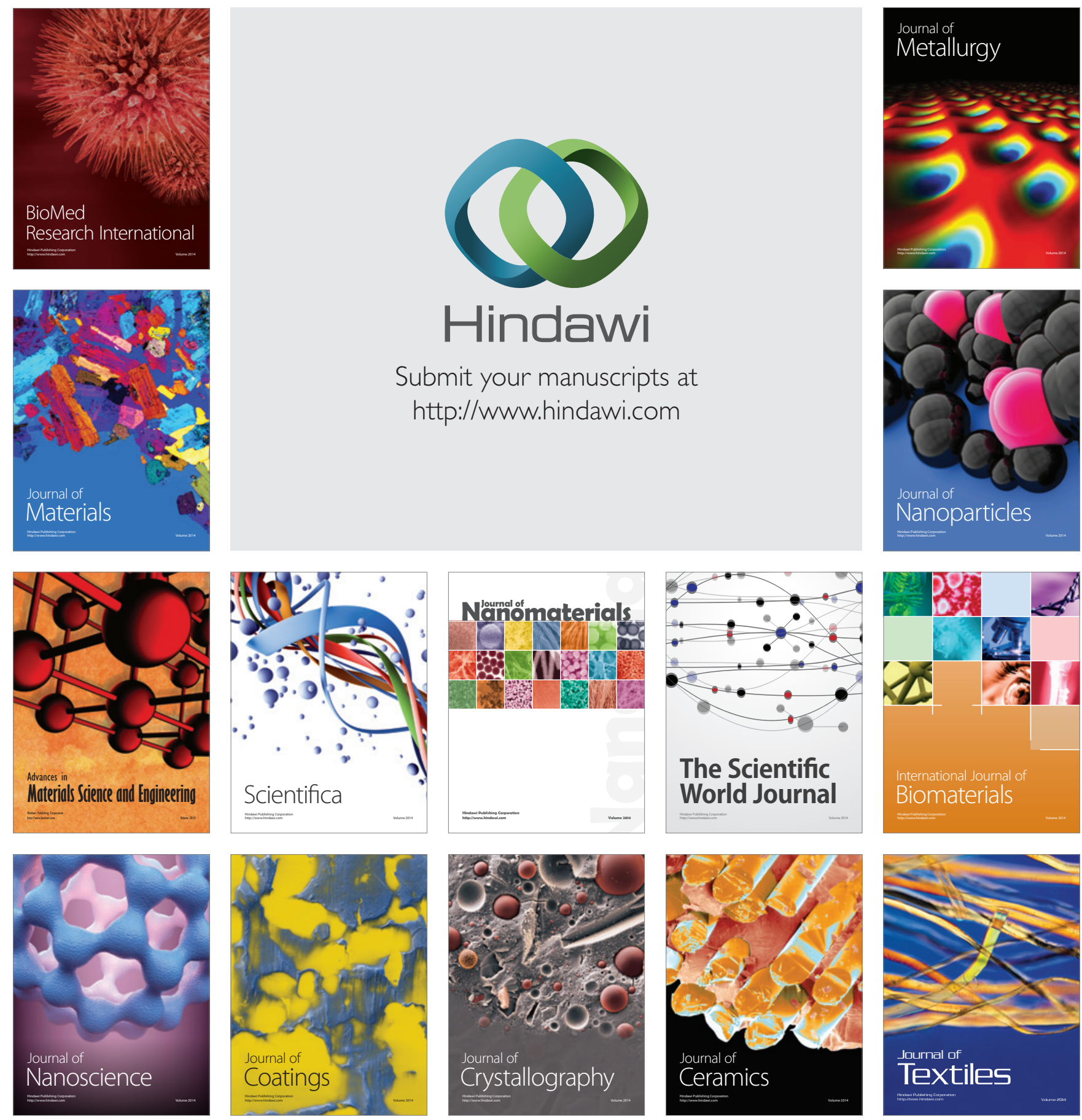